\title{
Aspectos Psicossociais Associados a Diferentes Fases do Transplante Hepático Pediátrico
}

\author{
Márcia Camaratta Anton ${ }^{1}$ \\ Hospital de Clínicas de Porto Alegre \\ Cesar Augusto Piccinini \\ Universidade Federal do Rio Grande do Sul
}

\begin{abstract}
RESUMO - Este estudo buscou investigar os aspectos psicossociais associados a diferentes fases do processo de transplante hepático pediátrico. Participaram do estudo seis mães de crianças com idades entre 4 e 8 anos e que haviam realizado transplante hepático há menos de seis anos. As mães responderam a uma entrevista que investigava sentimentos e vivências da família, nas diferentes fases da doença. Análise de conteúdo qualitativa mostrou intenso sofrimento emocional da criança e da família durante todo o processo. O período de espera e a cirurgia foram vivenciados como os mais estressantes, em virtude do medo intenso da morte. Os resultados apontam para importância do acompanhamento psicológico precoce e sistemático às crianças e às famílias, em todas as fases do processo.
\end{abstract}

Palavras-chave: transplante hepático pediátrico; fases do transplante; aspectos psicossociais.

\section{Psychosocial Aspects Associated to Different Phases of the Pediatric Liver Transplantation}

\begin{abstract}
This study aimed to investigate the psychosocial aspects associated to different phases of the pediatric liver transplantation process. The participants were six mothers of transplanted children aging 4 to 8 years old and who had undergone liver transplantation less than six years ago. Participants were interviewed on their feelings and family experiences during the different phases of the illness. Qualitative content analysis revealed that children and families suffered intensively during the whole process. The period of waiting for a donor and surgery were experienced as the most stressful because of the intense fear of death. The results enhanced the importance of early and systematic psychological assistance for the children and their families during all phases of the process.
\end{abstract}

Keywords: pediatric liver transplantation; transplant phases; psychosocial aspects.

O diagnóstico de uma doença crônica na infância, especialmente aquelas potencialmente fatais, é extremamente doloroso e traz profundas consequências emocionais para toda a família. Para algumas dessas doenças graves, progressivas, irreversíveis e não responsivas a nenhum outro tipo de tratamento, o transplante surge como uma terapêutica que pode aumentar a sobrevida e melhorar a qualidade de vida (Biagi \& Sugano, 2008; Farley \& cols., 2007; Jara \& Hierro, 2007; Simons, Ingerski \& Janicke, 2007). No entanto, o transplante é um procedimento complexo, que não implica apenas operar; não inicia e nem termina na cirurgia (Ferreira, Vieira \& Silveira, 2000). Tal procedimento envolve conhecimentos teórico-técnicos, cirurgias inovadoras, avançada tecnologia, intensa dedicação de inúmeros profissionais de várias especialidades e um tratamento contínuo que inclui uso ininterrupto de medicações, realização de consultas e exames invasivos, mesmo após o transplante (Farley \& cols., 2007; Ferreira \& cols., 2000). Portanto, não se pode considerar que o transplante leve à cura, já que a criança e a

1 Endereço para correspondência: Rua Ramiro Barcelos, 2350. Porto Alegre, RS. CEP 90035-903. Telefone/fax: (51) 33310536. Telefone comercial (HCPA): (51) 33598507. Telefone celular: (51) 92123724. E-mails: manton@hcpa.ufrgs.br; marciacamaratta@gmail.com; piccinini@portoweb.com.br. família continuam tendo que conviver com as limitações e privações impostas pela doença crônica e pelo transplante, havendo consequências para todos envolvidos em cada fase do processo (Anton \& Piccinini, 2010).

Em relação ao período diagnóstico, os sentimentos suscitados nos pais são intensos e diversos. Nesse momento, é comum o uso de mecanismos de defesa como a negação (Castro \& Moreno-Jiménez, 2005) e a evitação, ocorrendo também tendência à superproteção por parte dos pais (Anton \& Piccinini, 2010). Já no período de espera, costumam estar presentes sentimentos de ansiedade e impotência por ver o estado de saúde do filho piorando (Turkienicz, 2003). Além disso, podem ocorrer sentimentos de esperança, desamparo, competitividade com os demais pacientes em lista de espera, raiva, dúvida sobre a indicação de transplante e depressão (Castro \& Moreno-Jiménez, 2005). Apesar do sofrimento e da incerteza inerentes ao período de espera, o mesmo pode ser importante para que o paciente e a família se adaptem e aceitem melhor a necessidade de transplante (Olbrisch, Benedict, Ashe \& Levenson, 2002). Em virtude da possibilidade iminente de morte, a inclusão do paciente em lista de espera pode ser sentida como um alívio, por representar a possibilidade de viver e de mudar de vida (Massarollo \& Kurcgant, 2000). 
O procedimento cirúrgico, por sua vez, envolve inúmeros fatores: fantasias de castração, morte, destruição, ansiedades confusionais e paranóides (Aberastury, 1972; A. Freud, 1952), alteração na imagem corporal, regressão, medo da morte (Rinaldi, 2001), assim como frequentes sentimentos de culpa, dívida e fantasias acerca do doador (Masi \& Brovedani, 1999; Prug \& Eckhardt, 1976). Nesse sentido, a incorporação do novo órgão ao self constitui-se numa importante tarefa durante o período pós-operatório, sendo que aqueles pacientes que recebem um órgão de doador cadáver tendem a ter maior dificuldade de integração (Wray, Whitmore \& Radley-Smith, 2004).

Apesar de todas as dificuldades e demandas envolvidas numa situação de transplante, a qualidade de vida da criança (Engle, 2001; Jara \& Hierro, 2007; Kärrfelt, Berg \& Lindbled, 2000) e da família (Anton \& Piccini, 2010; Cole \& cols., 2004; Farley \& cols., 2007; Sokal, 1995), bem como o seu funcionamento emocional (Bucuvalas \& cols., 2003), tendem a melhorar com o tempo transcorrido desde o transplante, o que parece estar associado também à diminuição dos períodos de internação (Cole \& cols., 2004). Observa-se, ainda, que o resultado final de todo o procedimento do transplante depende não apenas do sucesso da cirurgia, mas também da habilidade do receptor e de sua família para fazerem as adaptações psicológicas necessárias ao sucesso do transplante (Prug \& Eckhardt, 1976).

Ainda existem poucas pesquisas examinando os aspectos psicossociais das diferentes fases do processo de transplante hepático infantil, que incluem o diagnóstico de doença irreversível, indicação de transplante, período de espera, pós-transplante imediato e tardio. A maior parte dos estudos enfoca as habilidades cognitivas e sociais das crianças já transplantadas (Tarbell \& Kosmach, 1998) ou psicopatologias mais prevalentes (Engle, 2001; Masi \& Brovedani, 1999). No entanto, a experiência da primeira autora do presente estudo tem mostrado que esse é um assunto relevante para a prática profissional, já que cada uma dessas fases tem suas peculiaridades e necessidades de atenção do ponto de vista psicológico, social e multidisciplinar. Assim sendo, o presente estudo buscou investigar os aspectos psicossociais das diferentes fases do processo de transplante ${ }^{2}$.

\section{Método}

\section{Participantes}

Participaram deste estudo seis mães de crianças transplantadas de fígado, que tinham idades entre 4 e 8 anos na época da coleta de dados, sendo que o tempo pós-transplante variou entre um e seis anos. Foi utilizado como critério de exclusão: transplante de urgência, doação intervivos, retransplante de fígado, terminalidade, comorbidade orgânica ou mental. O nível socioeconômico das famílias variou de baixo a médio, com base na escolaridade e profissão dos genitores. A Tabela 1 apresenta as características sociodemográficas das mães e dos pais, enquanto a Tabela 2 apresenta as características da doença de base das crianças.

\section{Procedimento e instrumentos}

Foi utilizado um delineamento de estudo de caso coletivo (Stake, 1994), buscando investigar os aspectos psicossociais das diferentes fases do processo de transplante, em famílias vivendo diferentes períodos pós-transplante. Durante as análises, buscou-se investigar tanto as particularidades como

2 Derivaram deste mesmo projeto de pesquisa outros três artigos que examinaram diversos aspectos do transplante hepático infantil: $O$ impacto do transplante hepático infantil na dinâmica familiar (Anton \& Piccinini, 2010); A experiência da maternidade no contexto do transplante hepático infantil (submetido); Desenvolvimento emocional em crianças submetidas a transplante hepático (submetido).

Tabela 1. Características sociodemográficas das mães e dos pais.

\begin{tabular}{|c|c|c|c|c|c|c|}
\hline Mãe /Pai & Idade & Escolaridade & Profissão & Trabalha & Filhos & Religião \\
\hline M1 & 36 & $5^{\mathrm{a}}$ série & Agricultora & Não & 1 & Católica \\
\hline P1 & 39 & $5^{\mathrm{a}}$ série & Agricultor & Sim & 1 & Católica \\
\hline M2 & 30 & $5^{\mathrm{a}}$ série & Calçado & Não & 2 & Evangélica \\
\hline $\mathrm{P} 2$ & 34 & $5^{\mathrm{a}}$ série & Calçado & Sim & 3 & Evangélico \\
\hline M3 & 26 & $2^{\circ} \mathrm{grau}$ & Confecção & Sim & 1 & Católica \\
\hline P3 & 28 & $2^{\circ} \mathrm{grau}$ & Motorista & Sim & 1 & Católico \\
\hline M4 & 35 & $2^{\circ} \mathrm{grau}$ & Autônoma & $\operatorname{Sim}$ & 3 & Católica \\
\hline P4 & 37 & $2^{\circ} \mathrm{grau}$ & Autônomo & Sim & 3 & Católico \\
\hline M5 & 41 & $2^{\circ}$ grau & Do lar & Não & 3 & Evangélica \\
\hline P5 & 48 & $2^{\circ}$ grau & Autônomo & Sim & 3 & Católico \\
\hline M6 & 49 & $5^{\mathrm{a}}$ série & Doméstica & Sim & 3 & Católica \\
\hline P6 & 43 & $2^{\circ}$ grau & Mecânico & Sim & 3 & Católico \\
\hline
\end{tabular}


Tabela 2. Características sociodemográficas e da doença das crianças.

\begin{tabular}{|c|c|c|c|c|c|c|c|c|}
\hline & Idade & Sexo & $\begin{array}{l}\text { Escolari- } \\
\text { dade }\end{array}$ & Diagnóstico & $\begin{array}{c}\text { Idade no diag- } \\
\text { nóstico }\end{array}$ & $\begin{array}{l}\text { Idade no trans- } \\
\text { plante }\end{array}$ & $\begin{array}{l}\text { Tempo pós- } \\
\text {-transplante }\end{array}$ & $\begin{array}{l}\mathrm{N}^{0} \text { internações } \\
\text { pós-transplante }\end{array}$ \\
\hline $\mathrm{C} 1$ & $7 \mathrm{a} 5 \mathrm{~m}$ & $\mathrm{M}$ & $1^{\mathrm{a}}$ série & HAI* & $5 \mathrm{a}$ & $5 \mathrm{a} 3 \mathrm{~m}$ & $2 \mathrm{a}$ & 3 \\
\hline $\mathrm{C} 2$ & $4 \mathrm{a} 8 \mathrm{~m}$ & $\mathrm{~F}$ & - & $\mathrm{AVB}^{* *}$ & $4 \mathrm{~m}$ & $2 \mathrm{a} 8 \mathrm{~m}$ & $2 \mathrm{a}$ & 0 \\
\hline $\mathrm{C} 3$ & $8 \mathrm{a} 4 \mathrm{~m}$ & $\mathrm{~F}$ & $2^{a}$ série & HAI & 1a $8 \mathrm{~m}$ & $7 \mathrm{a} 4 \mathrm{~m}$ & 1a & 5 \\
\hline $\mathrm{C} 4$ & $6 \mathrm{a} 5 \mathrm{~m}$ & $\mathrm{~F}$ & $1^{\mathrm{a}}$ série & AVB & $1 \mathrm{~m}$ & $8 \mathrm{~m}$ & $6 a$ & 1 \\
\hline $\mathrm{C} 5$ & $7 \mathrm{a} 8 \mathrm{~m}$ & $\mathrm{~F}$ & $2^{a}$ série & AVB & $1 \mathrm{~m}$ & 1a $1 \mathrm{~m}$ & $6 a$ & 4 \\
\hline C6 & $7 \mathrm{a} 7 \mathrm{~m}$ & M & $2^{a}$ série & AVB & $2 \mathrm{~m}$ & $2 \mathrm{a} 1 \mathrm{~m}$ & $5 a$ & 1 \\
\hline
\end{tabular}

Nota: *HAI - Hepatite Autoimune; **AVB - Atresia de Vias Biliares

as semelhanças entre os casos investigados. As famílias selecionadas com base nos critérios descritos acima foram convidadas a participar do estudo quando compareceram a consultas médicas ou por telefone. Todas as mães que aceitaram participar preencheram inicialmente a Ficha de Contato Inicial e assinaram o Termo de Consentimento Livre e Esclarecido. Horários individuais foram agendados para a realização da Entrevista sobre a história da doença e do transplante hepático infantil ${ }^{3}$, que abordava temas como: o desenvolvimento da doença (início, agravamento, cuidados necessários); notícia da necessidade de transplante; período pré, peri e pós-transplante; reações e percepção familiar em relação à doença e ao transplante. Trata-se de uma entrevista estruturada, desenvolvida pelos autores para fins do presente estudo, que foi realizada de modo semidirigido, tendo sido gravada e posteriormente transcrita.

\section{Resultados}

Análise de conteúdo qualitativa (Laville \& Dione, 1997/1999) foi utilizada para se investigar os aspectos psicossociais das diferentes fases do processo de transplante. Com base na leitura exaustiva das entrevistas, foram inicialmente criadas quatro grandes categorias temáticas. A primeira, denominada Reação ao diagnóstico da doença hepática e indicação de transplante, abordou o período de investigação diagnóstica e indicação de transplante; a segunda categoria, denominada Convivendo com a doença antes do transplante, enfocou todo o período que se estendeu do diagnóstico até a cirurgia, incluindo a entrada em lista ativa e o período de espera; a terceira categoria, denominada Chegada do órgão

3 Outros instrumentos foram utilizados em um segundo encontro, a saber: Entrevista sobre a experiência da maternidade e o relacionamento familiar no contexto do transplante hepático infantil, Entrevista sobre o desenvolvimento emocional da criança no contexto do transplante hepático infantil e o Teste das Fábulas. Os dados derivados destes instrumentos não foram utilizados no presente artigo, mas analisados naqueles citados na nota 2. e cirurgia, enfocou especificamente o momento da ligação telefônica que anunciou a chegada do órgão, a ida ao hospital, a entrada no bloco cirúrgico e o tempo de espera durante a cirurgia do transplante; a quarta categoria, Pós-transplante, incluiu desde os instantes após a cirurgia, até o momento da realização da entrevista para o presente estudo. Todas as entrevistas foram analisadas tomando-se por base essa estrutura de categorias temáticas. Apresenta-se, a seguir, cada uma das categorias, exemplificando-se com os relatos das próprias mães ${ }^{4}$. Após a apresentação dos resultados de cada categoria, discute-se os achados à luz da literatura.

\section{Reação ao diagnóstico de doença hepática e indicação de transplante}

Muitas das famílias cujas mães foram entrevistadas passaram por um processo diagnóstico longo (M1, M2, M3, $\mathrm{M} 6)^{5}$, sendo que todas as mães descreveram esse período como doloroso, repleto de incertezas, medos e informações contraditórias. A perambulação por diversos médicos, centros de saúdes e hospitais até encontrar o diagnóstico para a doença foi uma constante e algo relatado por todas as mães com muita angústia, em virtude da impotência que sentiam: "Naquela fase tu não sabe no que vai dar, tinha que esperar resultado de exame. Aquilo que é a parte mais difícil, uma fase de decisão, tava em cima do muro, não tinha nada resolvido" (M4).

Uma das mães (M1), apesar de toda a angústia que relatou, associada ao período diagnóstico, considerou que essa longa espera também teve um caráter preparatório em relação à dificuldade que seria enfrentar um transplante. Outras mães

4 Na dissertação de mestrado da qual o presente estudo deriva (http://hdl. handle.net/10183/12597) são apresentados inúmeros outros exemplos das falas das mães, os quais não foram incluídos no presente artigo em função de sua extensão.

5 Os relatos das mães foram identificados pela letra ' $M$ ' seguida pelos números de 1 a 6 , conforme Tabela 1 . As vinhetas foram editadas visando resumir o trabalho, sem comprometer o sentido das mesmas. 
(M2, M4, M6) comentaram ainda que o transplante era algo desconhecido para elas, o que causava mais insegurança e medo: "Ele ia ter que fazer um transplante, mas a gente nem sabia o que era isso” (M6).

A mãe cujo filho desenvolveu a doença mais tardiamente (M1) considerou que se o filho já tivesse nascido doente, talvez fosse mais fácil lidar com a indicação de transplante. Por outro lado, as mães cujos filhos foram diagnosticados em idade precoce (M2, M4, M5, M6) referiram a sensação de que os bebês eram frágeis demais para enfrentar tal situação: "Eu não conseguia imaginar que um bebê daquele tamanhinho ia fazer um transplante e ia ficar tudo bem" (M5).

O impacto causado pela notícia da necessidade de transplante foi um aspecto enfatizado por todas as participantes da pesquisa. A intensidade do momento em que foi feita a indicação de transplante pode ser exemplificada pela fala de uma das mães: "Aquilo pra mim foi uma ofensa. Eu disse: 'vamos embora, porque nesse hospital aqui são tudo louco. Ora, essa louca veio dizer que a minha filha vai precisar de um transplante. Vamos embora que meus pés aqui eu nunca mais vou botar", (M5).

Os sentimentos de choque, irrealidade, impotência, desamparo e medo também ficaram evidenciados em outras verbalizações: "Eu olhava pra ela e pensava: 'ela morreu. Perdi minha filha!' Porque eu não conseguia imaginar que fosse dar tudo certo. Eu olhava para ela e enxergava ela morta" (M5). Essa mesma mãe relatou seu desespero, desesperança e o impulso inicial de desistir de tudo. No entanto, ao ver que a vida de sua filha estava em jogo, arranjou forças para lutar.

No período inicial da doença, a negação apareceu com frequência como forma de defesa (M1, M4, M5): "Tu te apega em qualquer coisa pra acreditar que não vai ser nada. Eu tava bloqueada para qualquer outro tipo de informação. A minha primeira ideia foi negar a doença" (M4). Apesar das mães apontarem que o diagnóstico foi uma das piores fases, devido ao impacto que causou, sua definição também indicou um caminho a seguir: "Depois do diagnóstico era só lutar. Até ali eu tentava negar, tentava ver outra saida. Até que foi colocado que não tinha saída" (M6).

\section{Convivendo com a doença antes do transplante}

Após o diagnóstico da doença hepática, as famílias passaram por um período de evolução da enfermidade até o transplante, que variou de alguns meses a alguns anos. Nesse período pré-transplante, os genitores tiveram que lidar com a piora gradual do estado de saúde de seus filhos, cuidados, limitações e restrições impostas pela doença e pelo tratamento. Nesse sentido, mencionaram restrições alimentares, cuidados com quedas, higiene e infecções. As restrições alimentares foram relatadas pelas mães com muita ênfase. As que passaram pela experiência de ver seus filhos usando sonda nasoentérica (M2, M3, M5), em virtude da necessidade de ganhar peso, descreveram muito sofrimento: "Essa sonda eu nunca vou esquecer na minha vida, porque foi muito horrivel ver ela sofrer cada vez que ia colocar aquela sonda. Às vezes sangrava o nariz da menina” (M3). As restrições de movimento impostas pela utilização da sonda também foram muito enfatizadas por essas mães: "Ter que privar ela das brincadeiras por causa da sonda. Tu queria ver ela correndo, brincando, se divertindo, não ali, sentada, tomando leite" (M3). Algumas alternativas para lidar com essa situação e diminuir o sofrimento da criança foram buscadas pelas mães, como inventar jogos e brincadeiras que não exigissem movimentação física mais intensa: "Queria que ela esquecesse os períodos que tava tomando leite e nem percebesse que estava tanto tempo nisso ali" (M2). Uma das mães colocou que, no momento que entendeu a importância da sonda, passou a lidar melhor com aquela situação. Por outro lado, quando a sonda saía, essa mãe entrava em grande sofrimento, por medo de que aquelas horas sem alimentação fossem prejudicar o transplante.

Além desses cuidados e restrições enquanto a criança encontrava-se em casa, o envolvimento com o hospital e as internações longas e frequentes também fizeram parte da vida dessas famílias (M1, M3, M4, M5, M6). Nessas ocasiões, as mães acabavam permanecendo no hospital junto com os filhos, submetendo-se ao que fosse necessário para acompanhá-los: "Eu não queria deixar ele sozinho. Dormia até debaixo de bancos, num papelão e não morri com aquilo" (M6). Um dos pais também sentiu necessidade de ficar próximo, abandonando o trabalho para permanecer no hospital durante as internações.

Os procedimentos aos quais as crianças eram submetidas caracterizavam-se como outra fonte de sofrimento: "Era brabo tu ver toda hora a tua filha tomando injeção, escapava a veia, ai ela era perfurada. É inacreditável! Teve que raspar a cabeça, teve que ir nos pezinhos para pegar veia. Não tinha mais veia pra tanta aplicação de coisa. Aquilo para mim era a parte mais de tortura" (M4). Ao mesmo tempo, a consciência de que aqueles procedimentos eram necessários para a sobrevivência do filho estava presente em todas as mães e fazia com que conseguissem aceitá-los melhor. Algumas mães (M4, M6), no entanto, precisavam se afastar para que a equipe realizasse os procedimentos, já que não toleravam presenciá-los. A falta de qualidade de vida nesse período também foi ressaltada por uma mãe: "Do nascimento até o transplante a vida dela foi totalmente sem qualidade. Ela era doente!" (M5).

Durante as entrevistas, todas as mães afirmaram que após o diagnóstico de doença hepática, foram informadas que um dia, quando o quadro clínico piorasse, o filho precisaria entrar em lista de transplante. Mesmo com esse preparo anterior, a ocasião da entrada em lista ativa para transplante e a assinatura do termo de consentimento foram vivenciadas como aspectos bastante difíceis. Após a entrada em lista, a indefinição de quando seriam chamados para o transplante e a expectativa de poder receber a ligação telefônica a qualquer momento do dia ou da noite também causavam muita ansiedade. Todas as mães relataram ficar alertas: "Tava sempre na cabeça, sempre ligada! Sempre preparada para a hora que chegasse”(M2). O período de espera envolveu inúmeros sentimentos como ansiedade, medo e esperança: "Até fazer o transplante, eu vivia com angústia. Aquela espera” (M6). A expectativa das crianças mais velhas foi descrita pelas mães (M1, M3): "Se o telefone tocava, ela dizia: 'será que é o meu transplante?' Sempre naquela expectativa de transplante” (M3).

$O$ receio de que o filho morresse em lista de espera também se fez presente em todas as famílias: "A gente achava que ia perder ele antes dele chegar ao transplante” (M6). Outro 
aspecto relatado com bastante sofrimento foi ver o filho piorando dia-a-dia e não poder fazer nada, a não ser estar junto e esperar. "A pior coisa era tu ver ela morrendo, dia após dia. Uma tortura, um sofrimento! Era horrivel tu olhar pra tua filha ali gemendo, sofrendo daquele jeito. Nem gosto de imaginar mais como era aquilo. Era horrivel, horrivel!” (M3).

Algumas mães (M1, M3, M5) descreveram que, no início, queriam que o transplante demorasse a ocorrer, mas no momento em que viram seus filhos piorarem, começaram a torcer para que o transplante ocorresse logo. "Antes, não queria que tivesse que transplantar. Por fim, eu esperava aquele dia, todos os dias. Rezava para chegar aquela hora" (M3). A angústia vivenciada por essas mães e a luta contra o tempo ficaram claras no seguinte comentário: "Cada dia que passava era um dia vencido e era um dia a menos. Era um dia que ela tinha sobrevivido, mas eu sabia que era um dia a menos que ela tinha para viver, se ela não transplantasse. Era vitória e derrota. Era medo, sensação de medo" (M5).

O desespero de um dos pais levou a busca por todas as alternativas possíveis para conseguir um órgão que pudesse salvar a vida de seu filho. Após oferecer-se como doador vivo e ser contraindicado clinicamente, procurou a equipe médica para verificar se não seria possível comprar um órgão. A desconfiança em relação ao funcionamento da lista e a possibilidade de outros pacientes receberem vantagens também foi verificada (M1, M2): "Pensava: 'será que tem alguém mais importante que podia entrar na frente?' Mas depois a gente viu que tem fila mesmo" (M2).

As informações, explicações e apoio emocional fornecidos pela equipe multidisciplinar do hospital também foram mencionados pelas mães como algo de extrema importância. Algumas mães (M1, M2, M5, M6) referiram ainda o quanto se sentiam reconfortadas ao conversarem com mães de outras crianças transplantadas. Ao verem pessoas que já tinham passado pela mesma situação e que estavam bem, sentiam-se aliviadas e esperançosas: "Foi uma união muito grande. Eu me sentia acolhida. Eram todas as pessoas que faziam eu acreditar que tudo ia dar certo" (M5).

Por fim, o significado do transplante, de tirar um órgão de uma pessoa em morte cerebral e colocar em outra viva, foi citado apenas por uma das mães: "Tua filha vai passar por um transplante, tirar um órgão de uma pessoa que morreu e viver com aquilo ali, um órgão de outra pessoa! Começa a passar um monte de coisa na cabeça: 'como vai viver com o órgão de outra pessoa? '” (M3). A culpa sentida em relação ao fato de precisar que alguém morra para que o filho sobreviva foi expressa por outra mãe: "Meu Deus, eu não quero que ninguém morra'. As pessoas não entendem que tu só pede pra que a pessoa que vai ter que ir tenha o dom de fazer essa doação" (M5).

\section{Chegada do órgão e cirurgia}

A notícia da chegada do órgão causou tal impacto que ficou marcada na memória dessas famílias. Todas as mães relataram que, apesar de saberem que poderiam ser chamadas para o transplante a qualquer instante, o momento da ligação telefônica, que anunciou a chegada do órgão, foi muito intenso, causando ansiedade, desespero e agitação: "Fiquei baratinada, entrei em pânico. Eu corria pra tudo que é lado! A gente ficou perdido dentro de casa. A gente só atinou de pegar ele pra vir" (M6). A ocorrência de sentimentos contraditórios também foi relatada por muitas mães (M1, M3, M4, M5, M6): "Um medo muito grande, mas alívio. Muito alivio. Sensação de missão cumprida" (M5); "Foi tudo: alegria, choro, tristeza" (M6). A reação das duas crianças que tinham mais idade na época do transplante, por outro lado, foi descrita pelas mães como sendo de muita alegria: "Gritava: 'Chegou a minha vez! Chegou a minha vez! É um órgão pra mim!'. Gritava e ria. Maior felicidade, maior felicidade do mundo" (M3).

A ansiedade associada à chegada do órgão e à cirurgia foi tão grande que algumas mães (M2, M3, M5, M6) afirmaram que se desorganizaram emocionalmente. O sentimento de medo da morte foi novamente o mais constante e intenso. Ao olhar para seus filhos antes do transplante, a pergunta "será que verei meu filho vivo novamente?" surgiu com maior ou menor intensidade para todas as mães: "Eu chorava, porque era o dia que eu mais queria que chegasse, mas eu também sabia que podia ser o último dia que eu fosse ver ela viva, porque era um risco grande dela entrar e não sair" (M5). Em algumas circunstâncias, o receio foi tanto que uma das mães teve vontade de não ir ao hospital. "Medo! Medo de perda! Na hora, eu não sabia se eu ia, se eu ficava. O maior desespero! Dá uma vontade enorme de desistir do transplante" (M3). Apesar do medo vivenciado, o entendimento de que o transplante era a única alternativa de sobrevida para os filhos foi novamente o que deu força para enfrentar a situação: "Tinha que aceitar porque ele não tinha outra chance a não ser o transplante" (M1). Além da ansiedade e do medo, muitas mães (M1, M3, M4, M5, M6) destacaram o aspecto positivo vinculado à chegada do dia do transplante. "É uma esperança: vai dar tudo certo, ela vai melhorar, vai ser normal" (M4).

O momento da entrada no bloco cirúrgico e o período de espera durante a longa cirurgia de transplante também mobilizaram muita ansiedade e o medo da perda: "Aquelas 10 horas esperando é que são terrorismo. Não vinha ninguém, foi dando um aperto no peito, um desespero, vontade de entrar lá dentro e tirar ela de lá como eu tinha colocado. É horrivel!" (M3). A sensação de que não conseguiria aguentar a emoção foi descrita por uma mãe: "'Agora meu filho fica bem e eu morro!' Em cinco minutos não tinha mais cigarro porque eu fumava um atrás do outro. Eu nem fumava, comia o cigarro de nervosa" (M6).

Algumas mães (M3, M4, M6), apesar de sentirem-se angustiadas, sem notícias do que ocorria dentro do bloco cirúrgico, referiram também que se apavoravam quando chegava algum membro da equipe na sala de espera para dar notícias: “'Meu Deus, a [psicóloga] tá procurando eu?'Ai já bateu um desespero. Se a psicóloga tava me procurando, eu pensei 'ah, aconteceu alguma coisa!'” (M3); "A médica me chamou pra uma sala e eu pensei 'deu'. Pra mim, ela não tinha resistido. Sabe, quando te chamam de canto assim, a médica... Eu só respirei fundo e fiquei só escutando" (M4).

O final da cirurgia e as informações sobre o estado de saúde do filho foram recebidas com grande alívio. Uma etapa foi vencida. A criança sobreviveu a uma cirurgia grande, longa e de risco. Enfim, uma das mães descreveu o dia do transplante 
com muita propriedade, explicitando sentimentos subjacentes às verbalizações de todas as outras mães: "Na verdade, o dia do transplante é o dia do fim. Ou a pessoa termina aquele sofrimento ou parte para a vida nova e começa a colher tudo o que plantou até ali. Só tem duas coisas: ou dá certo ou dá errado. É o dia do fim" (M5).

\section{Pós-transplante}

No pós-transplante imediato, as crianças passaram por períodos distintos até receberem a alta. Nos primeiros dias ou semanas, habitualmente, todas as crianças transplantadas permanecem na Unidade de Tratamento Intensivo (UTI), onde são monitoradas com auxílio de diversos aparelhos. Apesar de saberem dessa rotina, as participantes da pesquisa consideraram que a primeira imagem dos filhos entubados e repletos de aparelhos de monitoramento foi chocante: " $O$ difícil foi quando a gente viu ele na UTI. Dava a impressão até que nem tinha vida. A gente sabia que tinha, que era só aquele impulso de desespero" (M1). Apesar das dificuldades da UTI e da consciência de que estar lá significava instabilidade do quadro, uma das mães referiu que se sentia bem na unidade, resistindo à alta para o quarto: "Era uma segurança ele estar lá dentro, pois quando foi para ir para o quarto eu tive medo" (M1).

Alegria e alívio ao ver o filho reagindo dia a dia foram descritos por todas as mães: "Eu nem via a hora passar, vendo que ela tava se recuperando, fazendo uma nova vida. Aquilo pra mim era tudo" (M3). Algumas mães (M2, M3, M6) relataram ainda o aumento visível na energia das crianças: "Já não era mais aquela menininha que ficava sentadinha. Ficou com uma energia! Só parava para dormir. O quarto tava pequeno para ela!" (M2).

A reação das mães à alta hospitalar variou bastante. Algumas ficaram muito felizes (M2, M3, M4), enquanto outras (M1, M5, M6), assustadas e divididas: "Eu tava querendo ir embora, mas o medo de ir e acontecer alguma coisa e... não dar tempo. Era toda uma situação nova, né?"' (M5). A expectativa das crianças mais velhas pela alta ficou evidenciada nas reações e verbalizações das mesmas. Um dos pacientes não conseguiu mais comer, nem dormir depois que soube da possibilidade de alta. $\mathrm{O}$ retorno para suas residências e a recepção na chegada também foram citadas pelas mães: "Eu chorava de emoção de chegar, de ver a minha casa de novo, né?” (M1).

A volta para casa após o transplante marcou uma nova fase, com novas expectativas, medos e ansiedades. $\mathrm{O}$ receio quanto à administração das medicações foi muito presente: "Os primeiros dias foram um pânico para mim, porque ela saiu com muito remédio” (M5). Os cuidados para não contrair infecção também foram enfatizados. Algumas mães (M1, M3, M5, M6) enfocaram os cuidados com a higiene: "Foi aquela agitação! O meu frigider que era marrom virou branco, de tanto passar álcool. Onde ele botava a mãozinha, tudo era limpo. O meu chão, um brilho! Álcool direto. Tudo que tivesse pra matar as bactérias eu comprava pra testar! Depois que ele brincava, eu colocava tudo de molho com água e vinagre"(M6). Outras mães (M1, M2, M3, M6) procuraram manter o mínimo contato com outras pessoas, inclusive familiares. Muitas delas só permitiram visitas após seis meses do transplante, passado o período de maior sucetibilidade da criança: "Ela ficou muito isolada em casa, por medo dela pegar uma infecção” (M3). O receio a respeito da possibilidade de rejeição do enxerto também foi trazido por uma mãe.

Todas as mães cujos filhos tinham realizado transplante há um até há dois anos mostravam-se ainda receosas quanto ao estado de saúde dos filhos, na época da entrevista, considerando com bastante seriedade todos os tipos de precauções. Algumas mães (M1, M3), mesmo sabendo que a equipe médica já havia liberado atividades físicas e diminuído as restrições, ainda preferiam manter a mesma rotina do pós-transplante imediato. Outras mães (M1, M4, M5, M6) procuraram ver os cuidados que precisavam ter com os filhos como preocupações "normais", que não os diferenciavam de nenhuma outra criança. No entanto, relataram com detalhes os cuidados que procuravam ter. Uma das mães, mesmo após citar que em sua casa as toalhas eram trocadas todos os dias, que o menino trocava de roupa cada vez que ia para rua e voltava para casa, que ele usava talheres, copos e pratos separados, tanto em casa como na escola, que não podia fazer brincadeiras mais agitadas, nem mexer em bichos, afirmou não haver diferença entre o cuidado do filho transplantado e o de crianças saudáveis: "Eu acho que o capricho faz parte da vida pra qualquer criança. Não só porque ele é transplantado” (M1). Da mesma forma, algumas mães (M1, M2, M4) referiram precauções com alimentação e higiene como questões normais, que todos deveriam ter: "Só cuidado que tem que ter a gente mesmo, né?" (M2).

Mesmo após as restrições terem diminuído e a vida começado a voltar ao normal, o receio dessas mães, em relação ao estado de saúde de seus filhos, permaneceu. Pôde-se constatar que situações que provavelmente seriam consideradas corriqueiras e lidadas sem maiores preocupações com filhos saudáveis, para essas famílias, independentemente do tempo transcorrido desde o transplante, geraram muita ansiedade. Isso ocorreu, provavelmente, por despertarem novamente o medo da morte, tão presente em suas vidas: "Têm intercorrências que dariam em qualquer criança, mas com ela eu fico mais apreensiva" (M5). Uma situação descrita por uma das mães mostrou a centralização das preocupações no transplante e no cuidado com o novo fígado: "Esses dias ela escorregou, deu de boca na porta e arrancou um dente. Eu já fui correndo: 'E a barriga, e a barriga?' E ela: 'não mãe, eu só arranquei um dente, "' (M3). Dessa forma, questões que provavelmente assustariam outras mães foram consideradas secundárias.

Duas mães (M5, M6) comentaram que, apesar dos filhos terem tido uma boa resposta ao transplante, sem reinternações após a cirurgia, o medo permaneceu presente por longo período (3 e 5 anos respectivamente). Uma dessas mães (M5), no momento da entrevista, já estava mais segura em relação ao estado de saúde da filha, mesmo quando havia alguma intercorrência: "Agora, tudo é mais tranqüilo, a gente se adaptou à situação” (M5). Já outra mãe, cuja filha teve várias intercorrências, ressaltou o quanto considerava difíceis as internações pós-transplante, comparando com o pré-transplante. Ao relatar essas situações, percebeu-se que essa diferença ocorreu, provavelmente, devido ao signifi- 
cado atribuído às internações nesses distintos momentos: "No transplante tava realizando um sonho. Agora é uma decepção, um verdadeiro túmulo" (M3).

Apesar dos percalços, as mães, de uma forma geral, relataram que, depois do transplante, a vida delas, da família e dos filhos foi se tornando mais tranquila e mais próxima do que imaginavam que seria se não houvesse a doença. Com o passar do tempo, foram se acostumando com os cuidados pós-transplante: "Cuidado a gente vai ter que sempre ter, o resto da vida, mas não é nenhum bicho de sete cabeças" (M3). Duas mães (M4, M5) comentaram que, às vezes, nem lembravam que os filhos eram transplantados e que a medicação era o único cuidado que permanecia. Ao mesmo tempo, esse era um cuidado que já havia sido incorporado à rotina, não causando dificuldades. Uma delas apontou que, na verdade, estava consciente que o risco de alguma intercorrência seria uma constante, mas considerou que o importante era a maneira como lidaria com isso: " $\mathrm{Na}$ verdade, tem um risco que se corre todos os dias, né? Não se corre, porque não se pensa e porque tá tudo muito bem" (M5). Duas mães (M1, M5) salientaram ainda que, antes do transplante, não imaginavam que isso aconteceria um dia: "Eu pensava: 'eu não vou perder meu filho, mas ir embora daqui, nunca mais'. Imaginava que ia ter que ficar perto do hospital, porque a gente não sabia se ele ia voltar a ser uma criança normal. E parece mentira, que tá lá correndo, voando, até mais do que é preciso" (M1). Uma das mães, que afirmou que a vida estava normal, sem "sequelas" do transplante, acreditava que isso só havia se dado pelo fato da menina ter sobrevivido. O sentimento intenso que surgiu ao ver que os filhos estavam bem depois de tudo que passaram também foi referido como algo muito importante na vida de todos: "É um sonho tu estar em casa, com ela transplantada. Passou aquilo tudo. Parece que tu vai acordar de um pesadelo!” (M3).

\section{Discussão}

Como pode ser visto, ao mesmo tempo em que o transplante hepático representou a única forma de sobrevida das crianças enfermas, tendo assim um significado positivo para essas crianças e famílias, ele também impôs um estilo de vida peculiar, não podendo ser considerado um procedimento isento de problemas médicos e psicossociais posteriores (Engle, 2001). Mesmo já passados alguns anos desde o transplante, a criança e a família continuaram tendo que enfrentar o desafio de viver à sombra de uma doença crônica que exige um regime de tratamento complexo e impõe uma série de vivências adversas e adaptações para todos os envolvidos (Anton \& Piccinini, 2010).

O período diagnóstico, como apontaram os resultados do estudo, foi vivenciado como um processo longo e especialmente angustiante, devido às incertezas do processo. Essa fase envolveu muito sofrimento emocional, não apenas associado ao luto pela perda do filho saudável, idealizado na gestação (Szejer \& Stewart, 1997), mas pela angústia e impotência na espera por um diagnóstico (Turkienicz, 2003). Nessa fase, a utilização de mecanismos de defesa como negação e evitação foi constatada, em algumas famílias, corroborando a literatura (Castro \& Moreno-Jiménez, 2005; Turkienicz, 2003). Outras, em contrapartida, enfrentaram essa fase com muita dor, por considerarem com extrema clareza o risco iminente de morte dos filhos. Além desses aspectos, o caráter preparatório que tal período representou para uma das mães cabe ser ressaltado, já que o transplante exige uma série de adaptações individuais e familiares, as quais se iniciam nesse momento, mas necessitam tempo para ocorrerem (Olbrisch \& cols., 2002).

Após a definição diagnóstica, as reações iniciais foram de desespero, choque e revolta, havendo a sensação de perda de referenciais. A intensidade do relato, tanto das mães que tiveram seus filhos transplantados recentemente, quanto daquelas cujos filhos haviam transplantado há mais de cinco anos, mostrou o impacto do diagnóstico na vida destas famílias, mesmo vários anos depois (Anton \& Piccinini, 2010). Para algumas, os temores e ansiedades surgiam mais, associados ao fato desse ser um procedimento sobre o qual não tinham conhecimento. Para outras, o fato de envolver a doação de um órgão de alguém em morte cerebral era intensamente impactante. Assim, como aponta a literatura, o transplante envolve não apenas o luto pela perda de parte do corpo, como em todas as cirurgias (Aberastury, 1972; A.Freud, 1952), mas a necessidade de incorporação de um órgão de outra pessoa (Prug \& Eckhardt, 1976; Wray \& cols., 2004) e a culpa pela necessidade da morte do doador (Masi \& Brovedani, 1999), sendo que esses fatores mostraram-se relevantes não apenas para os pacientes, mas para os próprios familiares.

Tendo em vista o forte impacto da notícia de necessidade de transplante, consideramos de extrema importância a qualidade da comunicação por parte da equipe de saúde, que envolve uma necessária sensibilidade e capacidade de empatia. Nesse sentido, cabe lembrar que, aquilo que no meio hospitalar tornou-se uma rotina e uma indicação reconhecida no caso de doenças irresponsivas a outros tipos de tratamento, para os familiares é algo tão assustador a ponto de uma das mães deste estudo, ao receber o diagnóstico, afirmar que não retornaria ao hospital.

Após a fase inicial envolvendo o diagnóstico, no geral, ocorre um período de luta contra a doença, seja por meio de uma colaboração ativa com os médicos ou por meio da negação da doença (Masi \& Brovedani, 1999). Esses aspectos também apareceram no presente estudo, sendo que a negação foi constatada especialmente no período inicial da doença, sendo posteriormente seguida por uma colaboração ativa, que tendeu a permanecer nos anos seguintes. Contribuiu para isto o estabelecimento de um vínculo adequado com a equipe, que auxiliou essas famílias na luta contra a doença de forma mais adaptativa e realística possível.

No período que se estendeu do diagnóstico de doença hepática irreversível até o transplante propriamente dito, o estado de saúde das crianças variou muito. Algumas ficaram, a maior parte do tempo, internadas e com muitas limitações físicas devido ao quadro clínico. Outras permaneceram em suas casas, conseguindo, até certo ponto, manter uma vida próxima ao esperado para suas faixas etárias. De qualquer forma, todas as crianças, em algum momento, foram submetidas a cuidados invasivos, como colocação e manutenção de sonda nasoentérica, realização de punções, cirurgia e internações hospitalares. 
A piora gradual do estado de saúde das crianças e a incerteza quanto à chegada do órgão também causaram extremo sofrimento aos pais (Turkienicz, 2003), tanto por verem seus filhos sofrendo, como pelo temor de que estes não sobrevivessem até o transplante. Além disso, constatamos que a assinatura do termo de consentimento para transplante e a entrada em lista de espera foram momentos muito difíceis e assustadores, já que representaram a confirmação da necessidade irrevogável de transplante, tornando a utilização de mecanismos de defesa como a negação, menos possíveis. Esses achados contrariam parcialmente a literatura que aponta a entrada em lista como algo que representa a possibilidade de viver e mudar de vida (Massarollo \& Kurcgant, 2000). Esses sentimentos só passaram a ocorrer, nas mães participantes da presente pesquisa, no momento em que a piora do estado de saúde dos filhos foi visível e o risco de morte tornou-se realmente iminente. Assim, enquanto as crianças estavam razoavelmente estáveis, o transplante era visto como um problema, passando a ser entendido como a solução, apenas diante da iminência de morte do filho. Dessa forma, o período de espera foi importante para que o paciente e a família pudessem se adaptar e aceitar melhor a necessidade de transplante (Olbrisch \& cols., 2002).

A notícia da chegada do órgão e a cirurgia foram momentos de extrema emoção. Para as crianças, despertaram sentimentos positivos, vinculados à esperança de cura e à redução do sofrimento ao qual estavam expostas. Para os pais e demais familiares, despertaram sentimentos contraditórios e intensos: por um lado, medo da morte; por outro, alívio e esperança de salvar a vida de seus filhos e melhorar a qualidade de vida. Contudo, para os genitores, o medo da morte ficou mais proeminente, sendo enfocado o fato daquele poder ser o último momento que veriam seus filhos vivos. Dessa forma, a ambivalência, expressada na dúvida de uma das mães em trazer o filho ao hospital para o transplante, pode ser entendida como uma reação natural dessas famílias diante do medo da perda. No entanto, se esta ambivalência torna-se muito intensa e o medo do transplante maior que a esperança de cura, isto pode levá-las a tomar atitudes perigosas, como adiarem a vinda ao hospital ou até mesmo não virem, aumentando as chances de óbito de seus filhos. Concluímos, portanto, ser de grande importância a atitude da equipe médica e multidisciplinar no sentido de informar aos pais sobre o curso da doença e a necessidade de transplante como a única alternativa de sobrevida para essas crianças, pois este foi um dos fatores destacados pelas mães como motivador para enfrentar o medo do transplante. Deve-se salientar, no entanto, que nem todas as atitudes e pensamentos dos pais são racionais, pois existem questões inconscientes e fantasias, por vezes poderosas, que podem interferir nesse processo e nas ações dessas crianças e famílias (Aberastury, 1972; A. Freud, 1952; Masi \& Brovedani, 1999; Prug \& Eckhardt, 1976; Wray \& cols., 2004). Dessa forma, consideramos fundamental um cuidadoso acompanhamento psicológico, assim como a avaliação psicológica pré-transplante, pois, por meio dessas intervenções pode-se detectar e trabalhar precocemente as possíveis fantasias, temores e a ambivalência dessas famílias, procurando prevenir, assim, intercorrências futuras.
Outro aspecto relevante foi o fato de todas as mães terem salientado a angústia de ficarem na sala de espera sem informações, durante uma cirurgia longa e de risco. Em suas falas, notou-se o quão intensas foram as emoções, as quais foram descritas com muitos detalhes e intensidade por todas as mães, independentemente do tempo transcorrido desde o transplante e da idade dos filhos na época da cirurgia. Assim, apesar das reais dificuldades institucionais que, muitas vezes, impossibilitam manter os pais informados, salientamos a importância de fornecer relatórios em intervalos de tempos regulares, a fim de tranquilizá-los. A regularidade desses relatórios parece ser importante como uma forma dos pais terem algum controle sobre a situação, já que o simples aparecimento de membros da equipe na sala de espera do Bloco Cirúrgico também foi relatado pelas mães como algo ansiogênico e associado a notícias negativas em relação ao transplante. Outro limitador, nesse sentido, é o fato de nem sempre haver membros da equipe de psicologia no hospital no momento do transplante, de forma que, por vezes, não se consegue realizar o acompanhamento dessa fase tão difícil para os familiares de pacientes transplantados.

O pós-transplante, por sua vez, envolveu diferentes períodos e ansiedades. Nos primeiros dias, enquanto a criança encontrava-se ainda no hospital, as famílias enfrentaram, principalmente, ansiedades referentes ao resultado do procedimento, à expectativa de cura ou morte. Nessa fase, a permanência na UTI foi estressante para muitas famílias, sendo que o aspecto mais difícil referido pelas mães foi o choque inicial ocasionado pela imagem do filho, inconsciente, repleto de aparelhos e curativos. Isso alerta para a real necessidade de um preparo para esses pais, a fim de diminuir tal impacto. Após esse primeiro momento, as mães sentiram alegria e alívio, associados à visibilidade da melhora do quadro clínico de seus filhos. Nesse sentido, as expectativas positivas se fizeram muito mais presentes do que os receios, para a maior parte das mães, já que o principal objetivo - a melhora da saúde de seus filhos - estava sendo atingido.

A alta da UTI e a do hospital despertaram ansiedades um pouco distintas das vividas até aquele momento, sendo que algumas mães ficaram ambivalentes, já que se sentiam seguras e sabiam que seus filhos estavam bem cuidados naquele ambiente. Por outro lado, a alta também representava a confirmação da melhora no quadro clínico e a possibilidade de retorno para a "vida normal" (Bucuvalas \& cols., 2003; Cole \& cols., 2004; Engle, 2001; Kärrfelt \& cols., 2000; Sokal, 1995).

A volta para casa foi vivenciada como uma nova fase, que envolveu novas ansiedades e medos. Os cuidados com medicações, higiene, infecção se tornaram assustadores para a maior parte das famílias, pelo menos nos primeiros meses pós-transplante, período em que as crianças transplantadas realmente estão mais vulneráveis. No entanto, algumas mães referiram que demoraram mais de três anos para se tranquilizar e habituar com a rotina. Já aquelas cujos filhos haviam transplantado há menos de dois anos, ainda continuavam receosas, mantendo os cuidados, mesmo quando a equipe já havia liberado algumas das restrições.

Outro aspecto a salientar é que o medo da morte ainda se fez presente, mas de uma forma menos intensa do que no período pré-transplante, sendo mais visivelmente des- 
pertado quando havia alguma intercorrência. Apesar das mães referirem com tanta ênfase os cuidados com o filho transplantado, de uma forma geral, procuraram entendê-los como questões normais que envolvem a saúde de todos os indivíduos e não como algo necessário devido à doença e ao transplante. Isso ocorreu, provavelmente, como forma de tornar a vivência o mais próximo do comum para todas as famílias. Outro fator que chamou atenção foi a centralização das preocupações em torno do transplante, de forma que, quando havia alguma intercorrência "comum" para qualquer criança, essas tendiam a ser sentidas como algo muito perigoso e ameaçador à vida. Já as situações em que poderia haver dano real, mas não houve, foram vistas como superficiais já que o fígado não havia sido atingido. Assim, a possibilidade de tornarem-se mais tranquilas, em grande parte, pareceu estar associada com o tempo transcorrido desde o transplante, assim como a resposta da criança a esse procedimento (Cole \& cols., 2004).

Nos casos em que as crianças tiveram internações pós-transplante, as mães referiram frustração, sendo que as internações eram sentidas como uma falha no processo. Apesar das mães relatarem que tinham clareza que essas intercorrências poderiam acontecer, evidenciou-se que, na verdade, a expectativa era de que elas nunca ocorressem. Isso mostra a negação dos riscos (Castro \& Moreno-Jiménez, 2005; Turkienicz, 2003) e uma certa idealização do procedimento, como forma de defesa.

Destaca-se aqui o fato de que, à primeira vista, poderia-se esperar dos pacientes e familiares expectativas de vida mais positivas já que passaram por uma situação de doença que ameaçou intensamente não apenas seu bem-estar físico e psicológico, mas sua vida. No entanto, os achados revelam uma vivência de muito sofrimento, durante todo o processo, muitas vezes associada ao fato de se sentirem diferentes das pessoas saudáveis. Isso porque o parâmetro de comparação continuou sendo os pares saudáveis e não tanto a condição de vida pré-transplante. Dessa forma, pode-se pensar que, embora as mães valorizem muito o fato do filho ter sobrevivido, isso não impede que se sintam frustradas por não conseguirem ter uma vida como imaginavam, para si mesmas, seus filhos e suas famílias.

Mesmo com todas as dificuldades envolvidas numa situação de transplante, resultados positivos para a dinâmica familiar e para a própria criança também foram aqui encontrados, principalmente quando comparados ao período pré-transplante (Anton \& Piccinini, 2010; Bucuvalas \& cols., 2003; Cole \& cols., 2004; Engle, 2001; Kärrfelt \& cols., 2000; Sokal, 1995). Com o passar do tempo, houve uma diminuição da ansiedade, sendo que aquelas mães cujos filhos transplantaram há mais de cinco anos referiram que a medicação era o único cuidado que permanecia, mas que este já havia sido incorporado às suas vidas. Todas as mães trouxeram muita alegria pelo fato de seus filhos terem conseguido transplantar e melhorar a qualidade de vida. Nesse sentido, o tempo transcorrido desde o transplante, assim como o sucesso do procedimento, as características pessoais e familiares foram fatores importantes para a melhor adaptação e qualidade de vida das crianças e suas famílias, o que corrobora achados da literatura (Bucuvalas \& cols., 2003; Cole \& cols., 2004; Kärrfelt \& cols., 2000; Sokal,1995).
Como limitações do presente estudo, pode-se apontar o fato de não se ter entrevistado os pais das crianças transplantadas. Dessa forma, obteve-se um panorama exclusivamente materno. Outro aspecto que deve ser destacado é o fato deste estudo ter sido retrospectivo. Em virtude disso, as lembranças maternas podem ter sofrido modificações com o passar dos anos, não refletindo com exatidão a vivência daquele momento. Além disso, foram entrevistadas somente mães de crianças que sobreviveram após o transplante. Dessa forma, pode-se pensar que essas mães tenham registros mais positivos dessa vivência do que aquelas que, apesar de todos os esforços, tenham perdido seus filhos. Cabe lembrar ainda que o estudo refere-se apenas a transplante hepático pediátrico. É provável que os resultados sejam válidos para outros tipos de transplante pediátrico, mas isso ainda precisa ser investigado.

\section{Considerações Finais}

Os resultados do presente estudo revelaram que, nas diferentes fases da doença, a criança e a família enfrentaram situações muito difíceis que causaram sofrimento e intensa ansiedade. $\mathrm{O}$ diagnóstico, o período de espera e a própria cirurgia foram vivenciados como as fases mais estressantes, tendo impacto importante para toda a família. Choque, desespero, perda de referenciais e impotência foram sentimentos comuns, sendo que houve uma necessidade de reestruturação pessoal e familiar para lidar com o transplante. Pode-se considerar que o tempo pré-transplante e a piora gradual do estado de saúde da criança serviram, de certa forma, como um preparo para o transplante. Assim, enquanto as crianças continuaram clinicamente estáveis, o transplante era visto pelas mães como um problema em suas vidas, do qual desejavam fugir. Apenas quando a mães viram concreta e fisicamente os sinais da doença, do deterioro e da morte é que o transplante passou a ser visto como uma solução. Todos esses aspectos surgiram, em grande parte, associados ao medo intenso da morte, que permaneceu presente mesmo após o transplante e a melhora do quadro clínico das crianças. Tendo em vista as várias consequências do ponto de vista psicossocial reveladas pelas mães no presente estudo, a indicação de acompanhamento multiprofissional se faz extremamente necessária no contexto da doença crônica envolvendo transplante. Do ponto de vista psicológico, cabe destacar a relevância de um acompanhamento psicoterapêutico sistemático à criança e à família, durante todas as fases do processo, visando diminuir o sofrimento psíquico, ao se propiciar um espaço terapêutico no qual as ansiedades parentais e infantis possam ser expressas e trabalhadas tecnicamente por profissionais qualificados, a fim de auxiliar na resolução de conflitos, com consequente diminuição de ansiedades subjacentes.

\section{Referências}

Aberastury, A. (1972). História de una técnica: preparación psicoterapéutica en cirugía. Buenos Aires: Paidós.

Anton, M. C., \& Piccinini, C. A. (2010). O impacto do transplante hepático infantil na dinâmica familiar. Psicologia: Reflexão e Crítica, 23, 187-197. 
Anton, M. C., \& Piccinini, C. A. (submetido). A experiência da maternidade no contexto do transplante hepático infantil.

Anton, M. C., \& Piccinini, C. A. (submetido). Desenvolvimento emocional em crianças submetidas a transplante hepático.

Biagi, A. U., \& Sugano, C. F. (2008). Transplante de órgãos. Em B. W. Romano (Ed.), Manual de psicologia clínica para hospitais (pp. 145-208). São Paulo: Casa do Psicólogo.

Bucuvalas, J. C., Britto, M., Krug, S., Ryckman, C., Atherton, H., Alonso, P., Balistreri, W. F., \& Kotagal, U. (2003). Health-related quality of life in pediatric liver transplant recipients: A single-center study. Liver Transplantation, 9, 62-71.

Castro, K., \& Moreno-Jiménez, B. (2005). Funcionamiento familiar en situación de trasplante de órganos pediátrico. Interamerican Journal of Psychology, 39, 383-388.

Cole, C. R., Bucuvalas, J. C., Hornung, R W., Krug, S., Ryckman, F. C., Atherton, H., Alonso, M. P., Balistreri, W. F., \& Kotagal, U. (2004). Impact of liver transplantation on health related quality of life in children less than 5 years old. Pediatric Transplantation, 8, 225-230.

Engle, D. (2001). Psychosocial aspects of the organ transplant experience: What has been established and what we need for the future. Journal of Clinical Psychology, 57, 521-549.

Farley, L. M., DeMaso, D. R., D’Angelo, E., Kinnamon, C., Bastardi, H., Hill, C. E., Blume, E. D., \& Logan, D. E. (2007). Parenting stress and parental post-traumatic stress disorder in families after pediatric heart transplantation. The Journal of Heart and Lung Transplantation, 26, 120-126.

Ferreira, C. T., Vieira, S. M. G., \& Silveira, T. R. (2000). Transplante hepático. Jornal de Pediatria, 76, 198-208.

Freud, A. (1952). The role of bodily illness in the mental life of children. The Psychoanalytic Study of the Child, VII, 69-81.

Jara, P., \& Hierro, L. (2007). Transplante hepático em niños. Gastroenterologia e Endoscopia Digestiva, 26, 239-243.

Kärrfelt, H. M. E., Berg, U. B., \& Lindblad, F. I. E. (2000). Renal transplantation in children: Psychological and donation-related aspects from the parental perspective. Pediatric Transplantation, 4, 305-312.

Laville, C., \& Dione, J. (1999). A construção do saber: manual de metodologia da pesquisa em ciências humana. (L. M. Siman, Trad.). Porto Alegre: Artes Médicas. (Trabalho original publicado em 1997)

Masi, G., \& Brovedani, P. (1999). Adolescents with congential heart diesease: Psychopathological implications. Adolescence, 34, 185-191.
Massarollo, M., \& Kurcgant, P. (2000). O vivencial dos enfermeiros no programa de transplante de fígado de um hospital público. Revista Latino-Americana de Enfermagem, 8, 66-72.

Olbrisch, M. E., Benedict, S. M., Ashe, K., \& Levenson, J. L. (2002). Psychological assessment and care of organ transplant patients. Journal of Consulting and Clinical Psychology, 70, 771783.

Prug, D., \& Eckhardt, L. (1976). Children's reactions to illness, hospitalization and surgery. Em A. M. Freedman, H. I. Kaplan \& B. J. Sadock (Eds.), Comprehensive textbook of psychiatry/II (pp. 2100-2108). Baltimore: The Williams \& Wilkins.

Rinaldi, G. (2001). Prevención psicosomática del paciente quirúrgico - causas y consecuencias del impacto psicobiologico de una cirurgía. Buenos Aires: Paidós.

Simons, L., Ingerski, L. M., \& Janicke, D. M. (2007). Social support, coping, and psychological distress in mothers and fathers of pediatric transplant candidates: A pilot study. Pediatric Transplantation, 11, 781-787.

Sokal, E. M. (1995). Quality of life after orthotopic liver transplantation in children. An overview of physical, psychological and social outcome. European Journal of Pediatrics, 154, 171-175.

Stake, R. E. (1994). Case studies. Em N. Denzin \& Y. Lincoln (Eds.), Handbook of qualitative research (pp. 236-247). Londres: Sage.

Szejer, M., \& Stewart, R. (1997). Nove meses na vida da mulher: uma abordagem psicanalitica da gravidez e do nascimento. São Paulo: Casa do Psicólogo.

Tarbell, S. E., \& Kosmach, B. (1998). Parental psychosocial outcomes in pediatric liver and/or intestinal transplantation: Pretransplantation and the early postoperative period. Liver Transplantation and Surgery, 4, 378-387.

Turkienicz, D. (2003). A experiência dos pais de pacientes à espera de transplante hepático infantil. Dissertação de Mestrado, PUCRS, Porto Alegre.

Wray, J., Whitmore, P., \& Radley-Smith, R. (2004). Pediatric cardiothoracic domino transplantation: The psychologial costs and benefits. Pediatric Transplantation, 8, 475-479.

Recebido em 17.07.08

Primeira decisão editorial em 15.05.10

Versão final em 19.07.10

Aceito em 19.07.10 